\title{
Traffic Noise Evaluation and Analysis in Residential Areas of Regina
}

\author{
L. Dai ${ }^{1 *}$, J. Cao ${ }^{1}$, L. Fan ${ }^{2}$ and N. Mobed ${ }^{3}$ \\ ${ }^{1}$ Department of Industrial System Engineering, University of Regina, Regina, Saskatchewan S4S 0A2, Canada \\ ${ }^{2}$ Department of Computer Science, University of Regina, Regina, Saskatchewan S4S 0A2, Canada \\ ${ }^{3}$ Department of Physics, University of Regina, Regina, Saskatchewan S4S 0A2, Canada
}

\begin{abstract}
Traffic noise produces unpleasant or unwanted sounds to the communities, which not only makes enormous noise pollution in the road areas but also detracts from the living and occupational quality of the buildings and land located near the main roads and highways. This study concerns road traffic noise impacts to the residential areas in Regina, the capital city of Saskatchewan, Canada. The present study aims at establishing a methodology to comprehensively understand the effects of traffic noise to different residential areas. The relationship among noise level, traffic flow and surrounding environment is studied. Extensive measurements are carried out in various typical residential areas carefully selected within the city. Systematic evaluations on traffic noise impacts to the residential areas of Regina are performed based on the data obtained in the acoustic measurements conducted in the study. Current noise levels in the residential areas of the three categories classified for Regina are presented. A numerical relationship between the traffic noise and traffic flow are established for the residential areas of the city.
\end{abstract}

Keywords: Evaluation, objective acoustic measurement, residential environments, traffic flow, traffic noise

\section{Introduction}

Motor vehicle, a significant symbol of modern civilization, not only brings convenient transportation to our society but also gives off unpleasant traffic noise in living environments. With the development of design and manufacture technologies, current single vehicle does emit less noise than those models manufactured years ago, but tremendous amount of vehicles have dissipated such reduction from single ones and the vehicles on the roads make the traffic noise the main noise source in cities, from towns to metropolitans. Research works have approved that noise may bring negative effects to people physiologically and psychologically. A clear view of the traffic noise level in living environments will certainly help to better understand the actual environment conditions and will indicate whether precautions or certain actions to the traffic noise are necessary.

In 1953, the publication of the Wilson Committee Report presented the world with the first comprehensive review of the problems of noise in modern society (Shaw, 1996). Major Canadian research covering traffic noise evaluation, annoyance study, sound barrier performance investigation etc was initiated in 1970's in Ontario (Harmelink and Hajek, 1972; Epplett and Gallagher, 1973; Johnston and Carothers, 1974; Hajek and Krawczyniuk, 1983). In Western Canada, several traffic noise studies were conducted in Vancouver, Calgary and Edmonton (Pyplacz, 1983; BCHEB et al., 1996; Love, 1986; ETPB, 1974). All these studies focused on the traffic noise in large-sized or medium-sized cities of Canada. Based

\footnotetext{
* Corresponding author: liming.dai@uregina.ca
}

on the archived documents available, however, there is still in lack of systematic traffic noise evaluations and studies for the residential areas in the cities of Saskatchewan, a province located in the middle west of Canada with total population around one million.

This study intends to assess the road traffic noise in various residential areas in Regina, the capital city of Saskatchewan. Regina is a typical Canadian city with population around 200,000, which contains miscellaneous function areas of commercial, administrative, industrial, tourist center, cultural institutions, governmental offices, schools, institutes and hotels etc., as well as the city roads of different classifications from national highways to streets in residential areas. The industrial areas of Regina locate relatively separately in the northeast part of the city. This prevents the industrial areas from being a main noise source to the residential areas. Within this city, the main roads and highways feature high traffic flow, some of which are very close to residential areas. In fact, traffic noise is the main noise source in Regina and it produces unpleasant sounds to the communities of the city. For controlling traffic noise and reducing the noise level in the residential areas of the City of Regina, a thorough understanding of the noise situation of the city both in daytime and nighttime are necessary.

In this study, traffic noise levels are evaluated for different residential areas in Regina via the systematic site measurements over the city. The residential areas, according to the traffic flow of their adjacent roads, are divided into three categories. The sampling locations are studied and selected for each of the categories to perform the site measurements and data collections at various times. Current noise situations 
in the residential areas of the city are analyzed with respect to the noise criteria widely accepted in Northern America. A numerical model, which reflects the relationship between the traffic flow and noise level in the residential areas of the City of Regina, is established.

\section{Methodology}

In acquiring noise data for traffic noise assessment, three important factors, namely observation time, observation location and noise indicators, need to be determined before the actual noise measurements can be performed in site. Moreover, one may need to take into consideration of the applied traffic noise measurement standards, the availability of site measurement resources and facilities, as well as the final measurement plan based on the research target.

\subsection{Observation Time}

In most traffic noise measurement practices, traffic noise observations are performed on the 24-hour or particular time section (e.g., 8 hours) bases. The measurements provide either continuous data records or intermittent data collections in the reference time intervals. Among the recent investigations, 24-hour continuous traffic noise observations were performed in Valencia, Spain (Gaja et al., 2003) and cities of Nigeria (Onuu, 2000). In Beijing, China (Li et al., 2002; Li and Tao, 2004) and Cario, Egypt (Ali and Tamura, 2003), noise data were recorded continuously in certain period of time of a day with respect to the corresponding national standards. Reference time measurement method was also reported to be applied for the noise surveys carried out in Caceres, Spain (Morillas et al., 2002) (15 minutes / 2 hours) and Valdivia, Chile (Sommerhoff et al., 2004) (20 minutes / 3 hours) respectively. With the considerations of Canada National Guidelines (requiring $\mathrm{L}_{24}$, Aeq as noise descriptor) (FederalProvincial Advisory Committee on Environmental and Occupational Health, 1989), ISO standards (International Organization for Standardization, 1995) and labor availability, this study adopts reference time observation, specified as: a 24-hour day is divided into twelve 2-hours intervals, and each measurement of the sampling lasts 15 minutes in each of the 2-hour intervals.

\subsection{Selection of Sampling Locations}

Morillas et al. (2002) summarized different strategies for studying environmental noise in a city, and four techniques of sampling-location selection were introduced. The first technique is to select sampling points by laying a grid over a map of target zone. The second and the third are source-oriented and receptor-oriented sampling respectively, and the fourth one selects the sampling points on the basis of a prior classification. The forth technique enables differentiation of the categories of a city's noise environment, as such, a relatively small number of sampling points may satisfactorily characterize the ambient noise of studied area. Taking advantage of the last method, with considerations of representative- ness of different residential areas and the daily traffic flow data available at the municipal government of Regina, ten sampling locations are selected, as shown in Figure 1, City Traffic Flow Map 2003 of Regina (Traffic Division, City of Regina, 2004).

The residential areas selected for the traffic noise measurements are classified into three categories as the following:

Category I: Residential areas adjacent to arterial road of daily traffic flow around 20,000 or above. For each category, at least three locations are selected for sampling. In order to locate the place with highest noise level, four potential locations near the roads with the heaviest traffic are studied. Locations 1, 2 and 4 in Figure 1 are among the busiest roads inside the city and Location 3 is at the Ring Road, which is part of the No. 1 Canada Highway.

Category II: Residential areas at the vicinity of streets, which connect city main roads with other minor streets in residential areas, including Locations 5 to 7 , featuring daily traffic flow in the range of 10,000 to 15,000 .

Category III: Streets in typical residential areas characterized by daily traffic flow less than 5000. Locations 8, 9 and 10 are in deep residential regions. There are quite limited public traffic in Location 8, and only neighborhood traffic in Locations 9 and 10. Location 9 represents apartment region, and Location 10 is in central part of residential area made up of typical Canada detached houses, chosen to represent typically quiet residential location.

\subsection{Measurement and Apparatus}

Measurements are conducted complying with Canada National Guidelines for Environmental Noise Control (Federal-Provincial Advisory Committee on Environmental and Occupational Health, 1989) and ISO Guidelines (International Organization for Standardization, 1995).

The data-sampling task is carried out from May to July 2004 during the spring/summer time of Canada, on weekdays and under ideal meteorological conditions, no wind and no rain. A 24-hour day is divided into two periods as daytime (7:00 - 23:00) and nighttime (23:00 - 7:00), and each period contains the corresponding number of 2-hour intervals. As a common practice, each measurement of the sampling lasts 15 minutes in each 2-hour interval. At every location, the sound level meter is placed on sidewalk, except for Location 4 ring road (highway) the equipment is set 15 meters from the centerline of the nearest driving lane (Shaw, 1971). The noise data acquisition is performed on both sides of the road on two randomly selected days. In referencing to the historical data collected by the Traffic Division, City of Regina, in normal weekdays without special community activities and under ideal weather conditions, the traffic flow behaves stable and repeatable in the same period of time of different observing days. Therefore, measurements complying with the aforementioned conditions on the randomly selected days provide reasonably accurate representative noise level of the communities. 


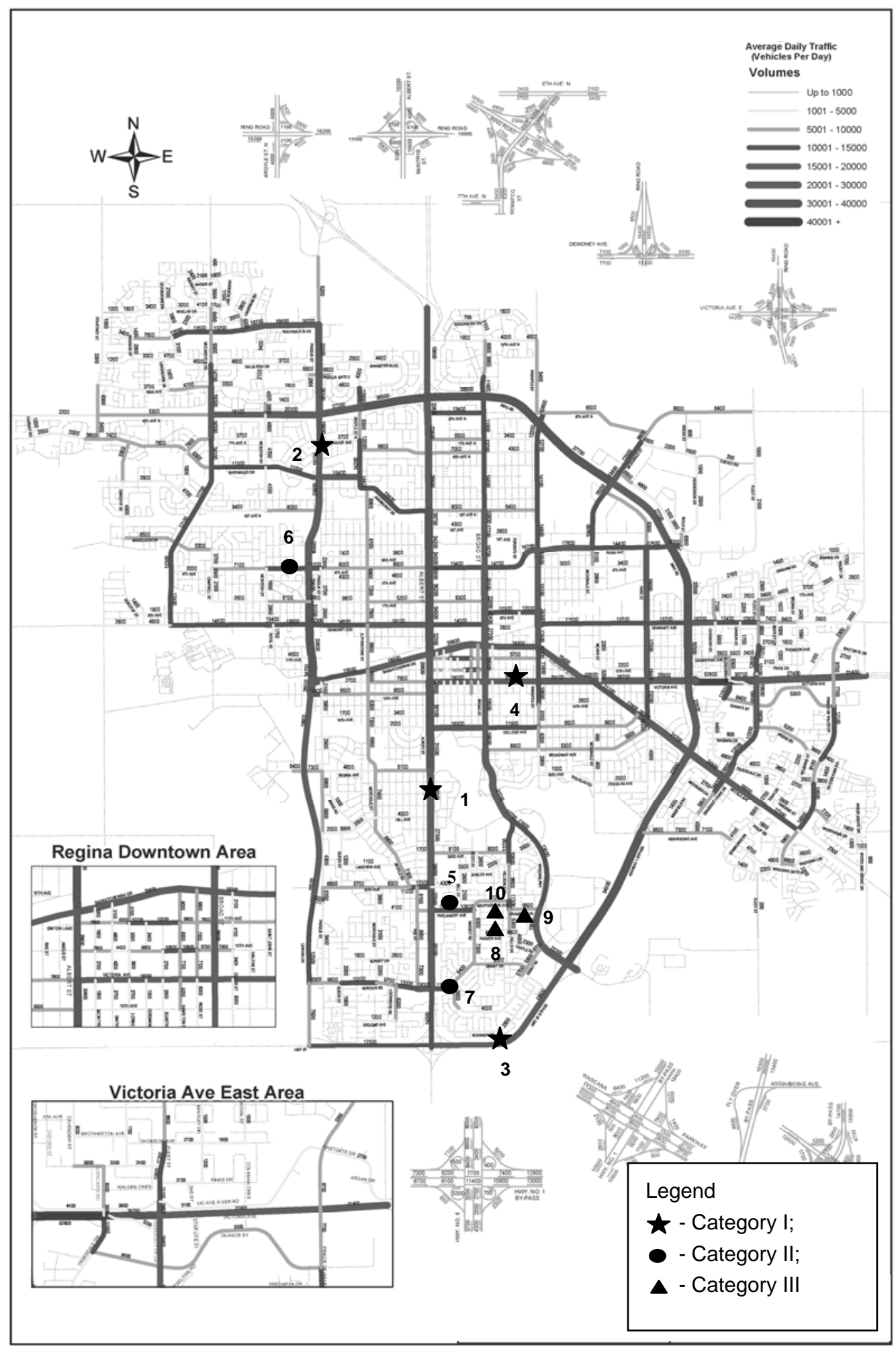

Note: 2004 traffic flow map for the city of Regina

Figure 1. Sampling locations. 
Bruel and Kjaer (B\&K) sound intensity level meter Observer 2260 is utilized for the data acquisition, with a $90 \mathrm{~mm}$ windscreen and a $1.3 \mathrm{~m}$ high tripod. On each day of noise data acquisition, before the actual site work, the sound level meter is calibrated by the B\&K Calibrator 4231 (Bruel and Kjaer, 1995 and 1998) for accurate and reliable data collection.

\subsection{Noise Indicator}

For the noise study, the sound intensity levels of each sampling locations $\mathrm{L}_{\text {Aeq }}, \mathrm{L}_{10}, \mathrm{~L}_{50}, \mathrm{~L}_{90}, \mathrm{~L}_{\max }$ and $\mathrm{L}_{\min }$ are recorded, where $\mathrm{L}_{\text {Aeq }}$ is the A-weighted equivalent continuous level over the time period of the measurement, $\mathrm{L}_{10}, \mathrm{~L}_{50}$, and $\mathrm{L}_{90}$ are percentile levels with the values exceed $10 \%, 50 \%$ and $90 \%$ of the elapsed time respectively, and $\mathrm{L}_{\max }$ and $\mathrm{L}_{\min }$ stand for the maximum and minimum sound levels detected. If not otherwise specified, sound level parameters used in this research are A-weighted. Daytime average level $\mathrm{L}_{\mathrm{D}}$, nighttime average level $\mathrm{L}_{\mathrm{N}}, 24$-hour average level $\mathrm{L}_{24}$, and day-night level $\mathrm{L}_{\mathrm{DN}}$ are defined and calculated later on. The $\mathrm{L}_{\mathrm{DN}}$ is similar to $\mathrm{L}_{24}$ but with $10 \mathrm{~dB}$ compensation for nighttime noise level in order to take into account of increasing annoyance of the noise over night sleep hours.

Noise indicator $\mathrm{L}_{24}$ and $\mathrm{L}_{\mathrm{DN}}$ are defined as the following:

$$
\begin{aligned}
L_{24}= & 10 \log _{10}\left[\frac { 1 } { 2 4 } \left(2 \times 10^{L_{7-9}}+2 \times 10^{L_{9-11}}+\ldots\right.\right. \\
& \left.\left.+2 \times 10^{L_{21-23}}+2 \times 10^{L_{23-1}}+\ldots+2 \times 10^{L_{5-7}}\right)^{1 / 10}\right] \\
L_{D N} & =10 \log _{10}\left[\frac { 1 } { 2 4 } \left(2 \times 10^{L_{7-9}}+2 \times 10^{L_{9-11}}+\ldots+2 \times 10^{L_{21-23}}\right.\right. \\
& \left.\left.+2 \times 10^{L_{23-1}+10}+\ldots+2 \times 10^{L_{5-7}+10}\right)^{1 / 10}\right]
\end{aligned}
$$

where the subscripts of $\mathrm{L}_{\mathrm{m}-\mathrm{n}}$ designate time from the $m^{\text {th }}$ hour to the $n^{\text {th }}$ hour.

$\mathrm{L}_{24}$ is a sound indicator representing the average noise exposure throughout a 24-hour day. This sound level can be used to reasonably represent the correlation of the community responses (BCHEB, 1996). However, $\mathrm{L}_{24}$ or $\mathrm{L}_{\mathrm{DN}}$ is not the best indicator for the peak-noise dominated cases, such as the intermitted noise generated by passing-by heavy trucks or setting-off aircrafts. For those cases, sound exposure level is measured (Bruel and Kjaer, 2000).

\section{Results and Discussion}

\subsection{Noise Level Analysis}

The acquired traffic noise level data and derived noise level indicators $\mathrm{L}_{\mathrm{D}}, \mathrm{L}_{\mathrm{N}}, \mathrm{L}_{24}$ and $\mathrm{L}_{\mathrm{DN}}$ are listed in Table 1 .

Based on the data in Table 1, the noise levels $\mathrm{L}_{\mathrm{D}}, \mathrm{L}_{\mathrm{N}}, \mathrm{L}_{24}$ and $\mathrm{L}_{\mathrm{DN}}$ are plotted in Figure 2. And 24-hour noise level curves are plotted in Figure 3. As can be seen from Figures 2 and 3, Location 1 is the place with the highest noise level among all the areas performed the measurements. Peak noise levels at this location are $\mathrm{L}_{24}$ with value of $69.1 \mathrm{dBA}$ and $\mathrm{L}_{\mathrm{DN}}$ of $71.9 \mathrm{dBA}$ respectively. The places marked as 1,2 and 3 in Figure 1 are the locations having higher noise levels in comparing with the rest of the places measured. The noise level $\mathrm{L}_{24}$ in these places are all over $67.0 \mathrm{dBA}$ and the noise level $\mathrm{L}_{\mathrm{DN}}$ are all above $70.0 \mathrm{dBA}$ as can be seen from Table 1 and Figures 2 and 3. The localized higher noise levels are contributed by heavier traffic flows in these places. In

\begin{tabular}{|c|c|c|c|c|c|c|c|c|c|c|c|}
\hline & & \multicolumn{4}{|c|}{ Category I } & \multicolumn{3}{|c|}{ Category II } & \multicolumn{3}{|c|}{ Category III } \\
\hline \multicolumn{2}{|c|}{ Location } & 1 & 2 & 3 & 4 & 5 & 6 & 7 & 8 & 9 & 10 \\
\hline \multirow[t]{4}{*}{ Day } & $\mathrm{L}_{10}$ & 73.8 & 72.9 & 71.6 & 69.4 & 70.4 & 71.8 & 68.5 & 63.9 & 53.0 & 48.8 \\
\hline & $\mathrm{L}_{50}$ & 68.0 & 66.2 & 65.5 & 62.1 & 63.0 & 65.6 & 60.8 & 54.9 & 45.7 & 44.6 \\
\hline & $\mathrm{L}_{90}$ & 59.7 & 57.9 & 58.2 & 54.4 & 55.8 & 57.5 & 53.5 & 46.6 & 43.5 & 42.3 \\
\hline & $\mathrm{L}_{\mathrm{D}}$ & 70.4 & 69.1 & 68.6 & 65.9 & 66.9 & 68.2 & 65.0 & 61.1 & 53.1 & 47.7 \\
\hline \multirow[t]{4}{*}{ Night } & $\mathrm{L}_{10}$ & 67.7 & 65.2 & 66.2 & 61.7 & 59.5 & 63.3 & 56.0 & 54.5 & 47.0 & 43.7 \\
\hline & $\mathrm{L}_{50}$ & 57.7 & 52.8 & 55.8 & 51.3 & 59.7 & 49.3 & 45.3 & 45.1 & 43.2 & 39.7 \\
\hline & $\mathrm{L}_{90}$ & 49.2 & 46.7 & 47.7 & 43.9 & 43.3 & 42.1 & 40.4 & 41.2 & 41.0 & 37.0 \\
\hline & $\mathrm{L}_{\mathrm{N}}$ & 63.8 & 61.7 & 63.0 & 58.5 & 56.9 & 59.6 & 56.4 & 51.8 & 46.2 & 42.3 \\
\hline \multirow{4}{*}{$\begin{array}{l}24 \\
\text { Hours }\end{array}$} & $\mathrm{L}_{10}$ & 72.6 & 71.5 & 70.4 & 68.0 & 68.8 & 70.3 & 66.9 & 62.4 & 51.7 & 47.6 \\
\hline & $\mathrm{L}_{50}$ & 66.4 & 64.5 & 63.9 & 60.6 & 61.4 & 63.8 & 59.1 & 53.3 & 45.0 & 43.5 \\
\hline & $\mathrm{L}_{90}$ & 58.1 & 56.3 & 56.6 & 52.8 & 54.2 & 55.8 & 51.8 & 45.4 & 42.8 & 41.1 \\
\hline & $\mathrm{L}_{24}$ & 69.1 & 67.7 & 67.4 & 64.5 & 65.3 & 66.7 & 63.5 & 59.5 & 51.8 & 46.5 \\
\hline \multicolumn{2}{|l|}{$\mathrm{L}_{\mathrm{DN}}$} & 71.9 & 70.2 & 70.6 & 66.9 & 66.9 & 68.7 & 65.5 & 61.3 & 54.4 & 49.8 \\
\hline \multicolumn{2}{|l|}{$\mathrm{L}_{\max }$} & 88.9 & 90.2 & 81.8 & 85.6 & 87.7 & 84.0 & 93.1 & 79.2 & 74.9 & 67.3 \\
\hline \multicolumn{2}{|l|}{$\mathrm{L}_{\min }$} & 40.2 & 38.7 & 32.7 & 40.3 & 36.5 & 37.7 & 35.5 & 33.2 & 35.0 & 32.4 \\
\hline
\end{tabular}
comparing the noise levels with the other locations, Locations 8, 9 and 10 in Figure 1 are remarkably quieter, as can be ob-

Table 1. Traffic Noise Level Data of Location 1-10 


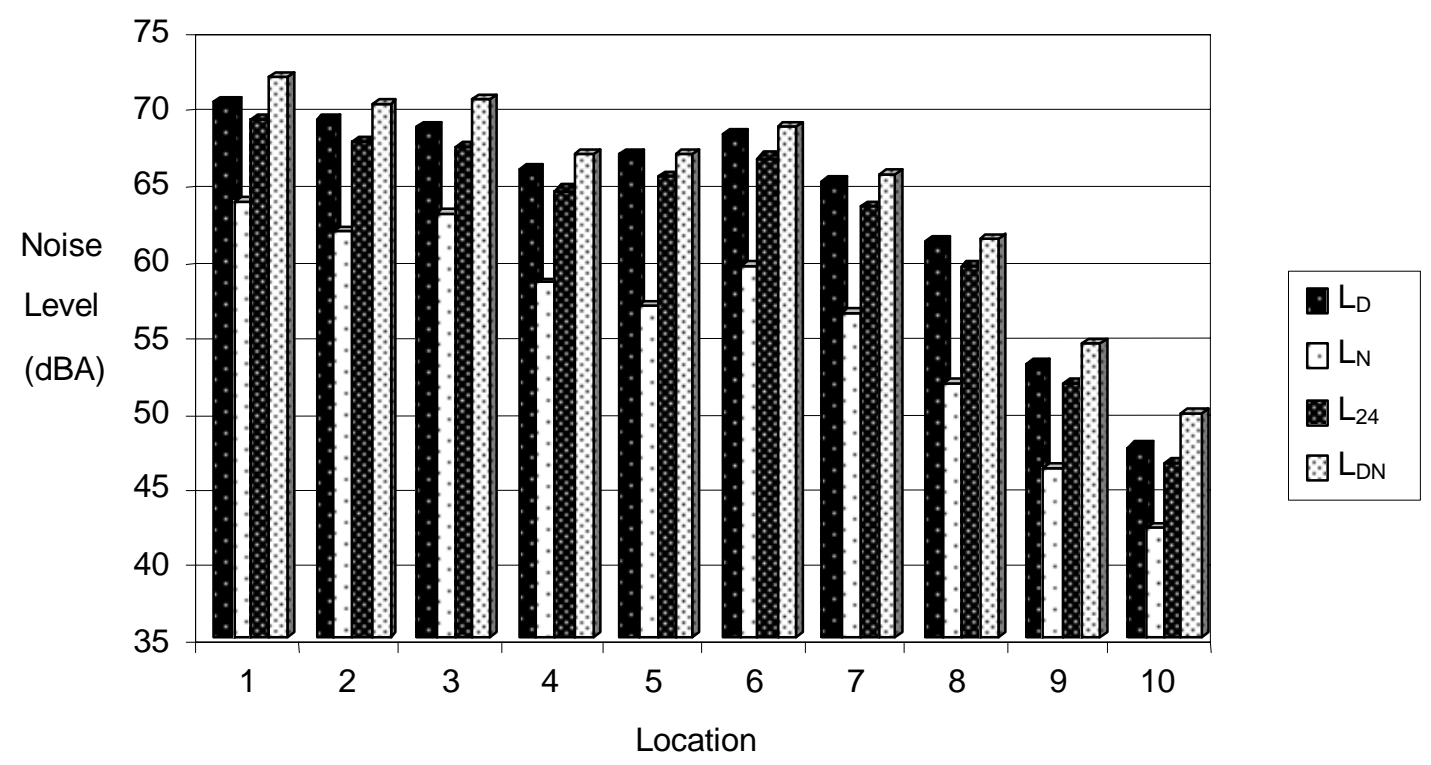

Figure 2. Noise level comparison among Locations 1 to 10.

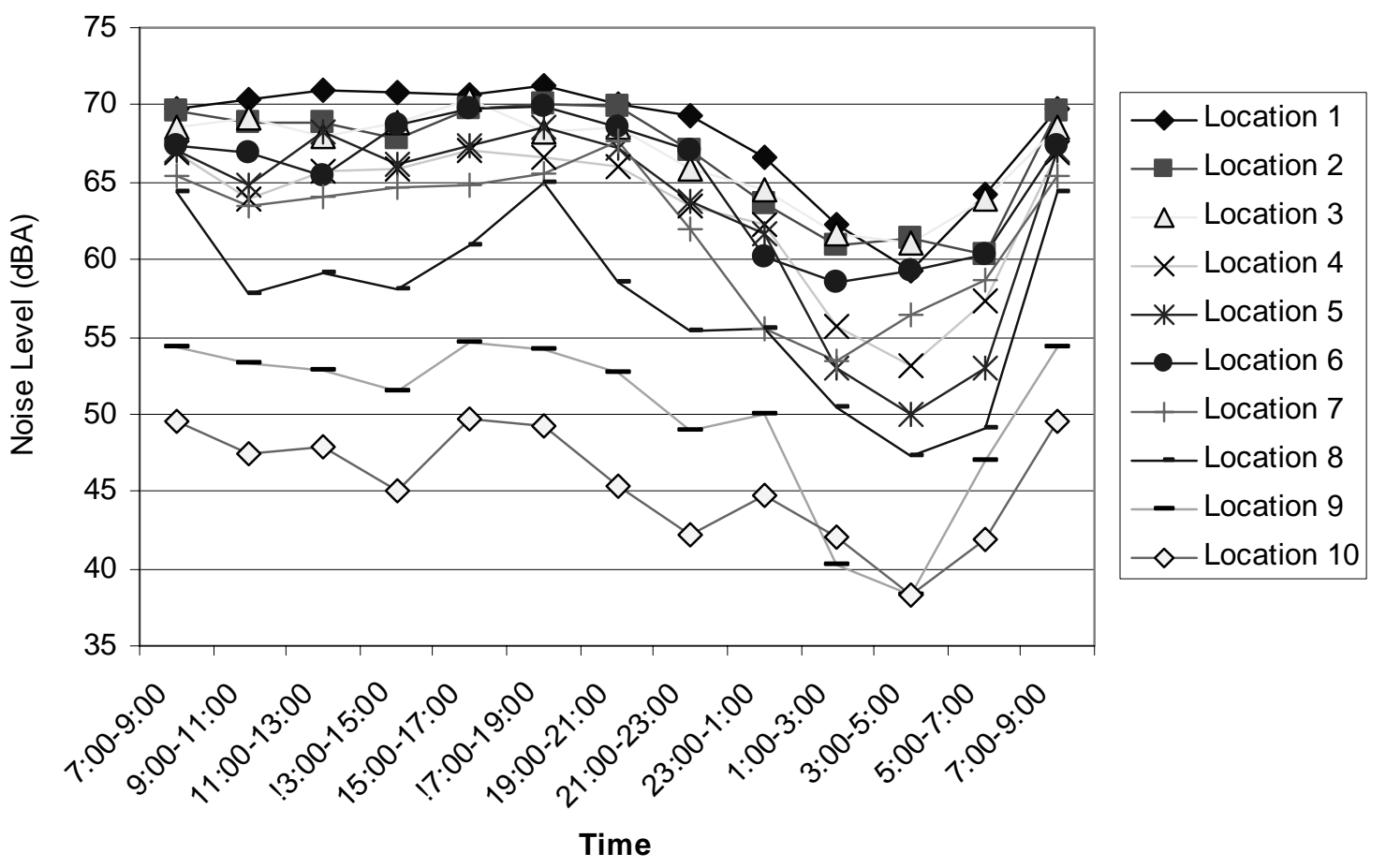

Figure 3. 24-hour noise level curves of Locations 1 to 10. 
served from Table 1. The noise levels at these locations are measured on the minor streets near or in the core part of the residential areas. Location 10 with $\mathrm{L}_{24}$ of $46.5 \mathrm{dBA}$ is the quietest place among all the sampling areas. For the sake of comparison of the noise levels over a day of 24-hour time period at the locations of the three categories defined, the $\mathrm{L}_{24}$ values are averaged. The averaged $\mathrm{L}_{24}$ taking from Table 1 are 67.2, 65.2 and 52.6 dBA for Categories I, II and III respectively. This implies that the sound level difference between Category I and Category II is not very large. However, the difference can be clearly distinguished by human ears. In terms of averaged $\mathrm{L}_{24}$, the noise level of the areas of Category III is the lowest in comparing with that of the other two categories. In fact, these areas are significantly quieter than the areas of categories I and II. These results agree well with that obtained in the South Shore traffic noise study performed in Vancouver (BCHEB et al., 1996), where the traffic noise level $\mathrm{L}_{24}$ along the major streets is in the range of 64-69 dBA and the value drops to 49-57 dBA along local interior streets.

$\mathrm{L}_{90}$ can be used as an indicator of background noise level since it reflects the sound level exceeded $90 \%$ of the time (Bruel and Kjaer, 2000) and the effects of peak noise data during the measuring time become insignificant, therefore, $\mathrm{L}_{90}$ is an indicator of long lasting noise in a specified area. On the other hand, $\mathrm{L}_{10}$ indicates the highest sound levels detected in $10 \%$ of elapsed time, and the effects of the peak noise dominate this value. It can be found from Table 1 that the values of $\mathrm{L}_{90}$ in residential areas of Categories I and II are higher than that of $\mathrm{L}_{10}$ at the Locations 9 and 10 . One may therefore conclude that the environmental noise in the areas of Categories I and II is much worse than that of Category III. In considering the overall lower noise levels in the areas of Category III, the environment of these areas is much better than that in Categories I and II. An environmental sound level in Location 10, as an example, makes the residents at this location feel little noise variation indoor and outdoor. The difference of $\mathrm{L}_{24}$ values between the Locations 1 and 10 reaches $22.6 \mathrm{dBA}$. This is a remarkable sound level variation to human ears. It is well understood that the subject feeling of sound level difference of $10 \mathrm{~dB}$ is significantly noticeable (Bruel and Kjaer, 2000).

The noise level in Location 4 is evidently lower than that of the other areas of the same category, as can be seen from Table 1 and Figure 2. This explains the effects of a $40 \mathrm{~km}$ speed limit at this location 4. The measurement at Location 6 of Category II shows higher noise level in comparing with the other two areas of the same category. The relatively high noise level at Location 6 is due to the narrower street at this location. The street only consists of two driving lanes in comparing with the 4 driving lanes at Location 5 and 7. Under the conditions of similar traffic flow level, the traffic density in each lane at Location 6 is doubled, therefore, leading to the higher noise level in this area.

Based on the National Guidelines for Environmental Noise Control by Federal-Provincial Advisory Committee on Environmental and Occupational Health (CEOH) (1989), a generally acceptable road traffic noise level $\mathrm{L}_{\mathrm{D}}$ for residential areas should be less than $55 \mathrm{dBA}$ and for night, $\mathrm{L}_{\mathrm{N}}$ should not be greater than $50 \mathrm{dBA}$. This is similar to the recommendation of World Health Organization (WHO) (1999), 55 dBA for outdoor areas. WHO also established a regulation that the average noise level $\mathrm{L}_{\text {Aeq }}$ inside a residential house should not exceed $30 \mathrm{dBA}$ between 9:00 p.m. and 7:00 a.m. and that the maximum in-house noise level should not exceed $45 \mathrm{dBA}$ at any time. An area with environmental noise level less than 55 dBA is usually considered as a comfortable environment with little or no annoyance so that no negative physical and mental influence will be caused to essential activities such as working, leisure and sleeping. However, to most cities in Northern America, this requirement is rather strict. Based on the present research, the requirement of $\mathrm{L}_{\mathrm{Aeq}} \leq 55 \mathrm{dBA}$ is difficult or impossible to achieve in the areas near the streets with continuous traffic. With the sound level meter placed on sidewalk, $\mathrm{L}_{\text {Aeq }}$ measured is very likely over $55 \mathrm{dBA}$ if there is one or two small-size vehicles passing by in a minute.

Another widely accepted standard is the one issued by the US Department of Housing and Urban Development (HUD, 1985), which recommends that an acceptable noise level is $\mathrm{L}_{\mathrm{DN}} \leq 65 \mathrm{dBA}$; normally unacceptable noise level as $65 \mathrm{dBA}<\mathrm{L}_{\mathrm{DN}} \leq 75 \mathrm{dBA}$; and unacceptable as $75 \mathrm{dBA}<\mathrm{L}_{\mathrm{DN}}$. This standard is less restrictive than that of $\mathrm{CEOH}$ and $\mathrm{WHO}$.

Among all the areas performed the noise level measurements, only the residential areas like Locations 9 and 10 are acceptable in terms of the noise levels per the recommendations of CEOH and WHO. If the standard of HUD is considered, the dwelling areas like Locations 8, 9 and 10 are under normally acceptable situation and the noise levels of the other areas are still not acceptable. It may therefore state that the environment of Regina's places that fall in Categories I and II does not satisfy the recommended noise limit requirements according to the existing standards in Northern America. This statement reflects the unsatisfactoriness and complaints of the residents living in the areas of Category I regarding the displeasure environment and traffic noise annoyance suffered by the people in the communities.

In evaluating the effects of noise on the communities, speech interference, annoyance and sleep disturbance are the three principal aspects (BCHEB et al., 1996) to be considered. Effects of traffic noise to the communities especially the communities falling in Category I are assessed as the following with respect to the three aspects.

\section{(1) Speech Interference}

Speech intelligibility is strongly affected by the speech interference created by noise. When speeches are masked by noise, speech communication quality is interfered. A background noise level less than $55 \mathrm{~dB}$ is necessary for a satisfactory outdoor communication with normal voice level at a distance of $3 \mathrm{~m}$ with an acceptable speech indelibility of $95 \%$ (Shaw, 1996). For a relaxed conversation with normal voice level in a typical living room, a background noise level not greater than $45 \mathrm{~dB}$ is required to provide $100 \%$ sentence intelligibility throughout a room (Shaw, 1996). As shown in Figure 4, Speech Interference Noise Effects by NASA (Shaw, 1971) gives similar information. Therefore, residents in the 
areas of Categories I and II may have outdoor speech interference caused by traffic noise once a while, particularly in Locations 1, 2 and 3. People living adjacent to Location 3, Ring Road (highway), experience more speech interference than any other locations, because usually there are heavy trucks (around $10 \%$ of the total vehicles traveling on the Ring Road in the time other than rush hours) that emit intermittent high environmental noise. The noise level there can be as high as $80 \mathrm{~dB}$ and above. Outdoor conversation in these locations is difficult.

\section{(2) Annoyance}

Annoyance is essentially a subjective response, varying from person to person. Annoyance can occur at relatively low average noise level particularly when intrusive noises are produced or a noticeable sound change happens in the environment. In general, annoyance evaluations consider equivalent sound level, penalty for impulses, penalty for tone and information content, penalty for time of day, and penalty for certain sources and situations. Among these considerations, equivalent sound level is a key factor. Based on the data collected for the present research, the residents near the Ring Road are most annoyed, as in this area not only the $\mathrm{L}_{24}$ is high but also there are occasional transient sounds of high-pressure levels from passing-by heavy trucks containing strong low-frequency components. Noise in the locations with high value of $\mathrm{L}_{24}$ tends to be more annoying. For a thorough evaluation on annoyances caused by traffic noise, a detailed study considering all these factors is needed.

\section{(3) Sleep Disturbance}

The high level intrusive sound in environment such as passing-by heavy trucks can affect sleep quality with sleep delaying, unwanted awakening, and deep-stage sleep interference. Based on the survey of the present research, there is no evidence of obvious sleep disturbance found among the residents in Regina by traffic noise. Although a comprehensive subjective assessment on sleep disturbance has yet to be conducted, the responses collected so far from some of the residents in the areas of Category I show that they still consider indoor noise level acceptable and no remarkable sleep disturbance are experienced by the residents when doors and windows are firmly shut. However, in all the residential areas conducted with the traffic noise survey, sleep disturbance may still occur due to other occasional disturbance such as sirens, road constructions, etc.

In the sequence listed above, the most negative effect caused by traffic noise is the disturbance on speech intelligence, followed by annoyance and sleep disturbance in city of Regina. Although these negative influences from traffic noise take place at some locations in the city especially the areas falling in Category I, the traffic noise levels for most residential areas of Regina can still be considered as acceptable in general and the noise disturbance to the large percentage of population is not serious. As found in the present research, the majority of the population in Regina lives in the areas of Category III, the areas similar to that of Location 8 - 10 where traffic noise is relatively low.

\subsection{Numerical Relationship between Traffic Flow and $L_{\text {Aeq }}$}

Traffic noise heavily relies on traffic flow to which the noise levels are measured. Establishment of a relationship for traffic noise and traffic flow is thus critical for the quality of a traffic noise assessment for a city. However, the relationship between traffic noise and traffic flow is also affected by the road constructions and road surface conditions of the city regarded. Therefore, for systematically analyzing the traffic noise circumstances in the city of Regina with reliable results, it is significant to establish such a relationship. The data of traffic flow collected are plotted in Figure 5 with respect to the corresponding traffic noise levels measured. A logarithmic relationship between the traffic flow and traffic noise is then established on the basis of the noise data acquired. This relationship is also plotted in Figure 5 and the numerical relationship can be expressed in the following equation for the data available.

$L_{\text {Aeq }}=4.0781 \operatorname{Ln}(Q)+39.315$

where $\mathrm{Q}$ is the traffic flow with unit of number of vehicles per hour.

In a general form, based on the analysis of the present research, the relationship between traffic noise and traffic flow can be given as

$L_{\text {Aeq }}=A \times \operatorname{Ln}(Q)+B$

where $\mathrm{A}$ and $\mathrm{B}$ are the constants relating to road and traffic conditions and can be determined with a field noise measurement process and noise data analysis similar to that performed for this research. With the relationship shown in Equation (4), traffic noise level of a given road can be quantified once the constants of $\mathrm{A}$ and $\mathrm{B}$ are determined and the traffic flow of the road is known. Establishment of such a relationship is significant for engineers and researchers to evaluate the traffic noise intensity of a specified road with a given traffic flow, which is usually available to a Canadian city. On the other hand, if the traffic noise level of a road is specified, per the regulations set forth by the government or organizations, the maximum allowable traffic flow for this road can also be determined with the relationship.

\section{Conclusive Remarks}

The traffic noise of residential areas in the city of Regina is studied by classifying the roads into three categories and conducting the objective field measurements. According to the abovementioned road traffic noise limits of Canada, recommended noise level from WHO, and standards issued by HUD, the environmental noise in the locations of Categories I and II does not satisfy the standards due to the traffic noise in the vicinities of the locations. Whether the indoor noise levels comply with WHO recommendations mainly depends on the sound sealing conditions of the houses. Well-sealed windows 


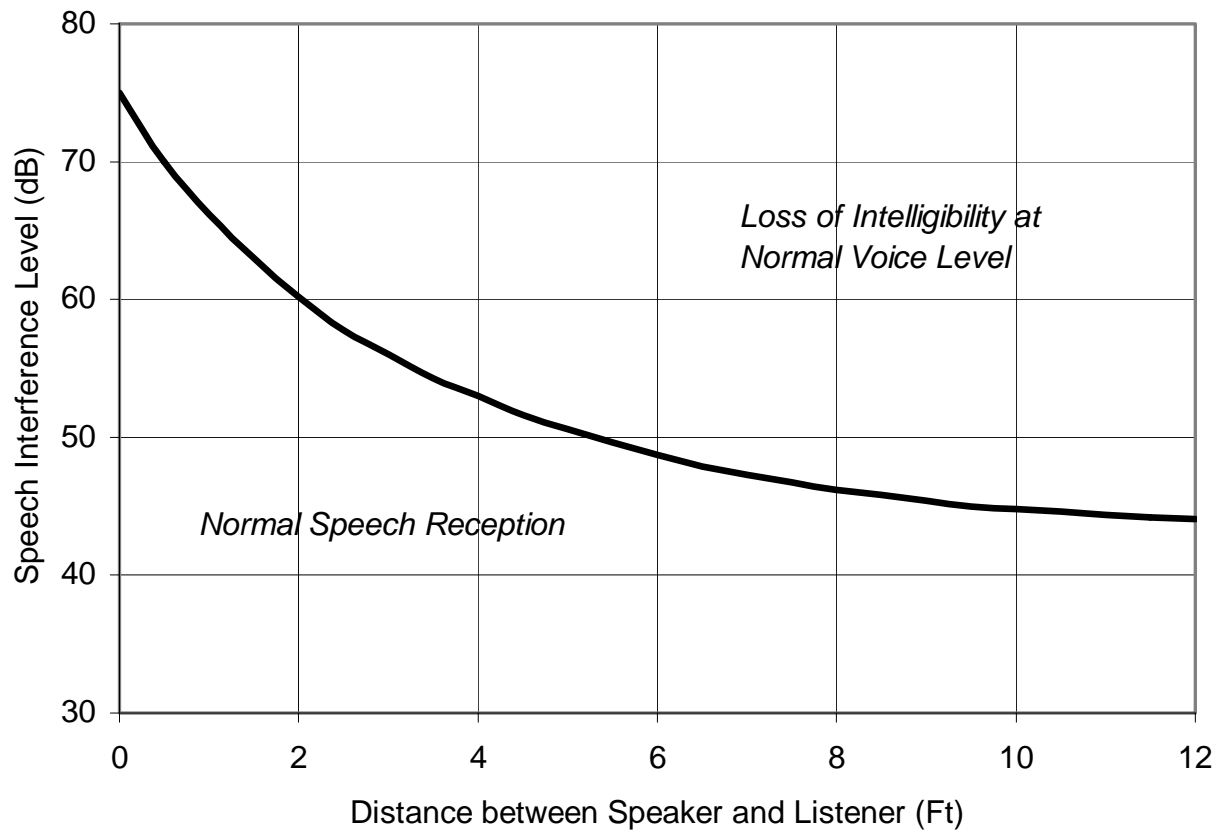

Figure 4. Speech interference noise effects by NASA (Shaw, 1971).

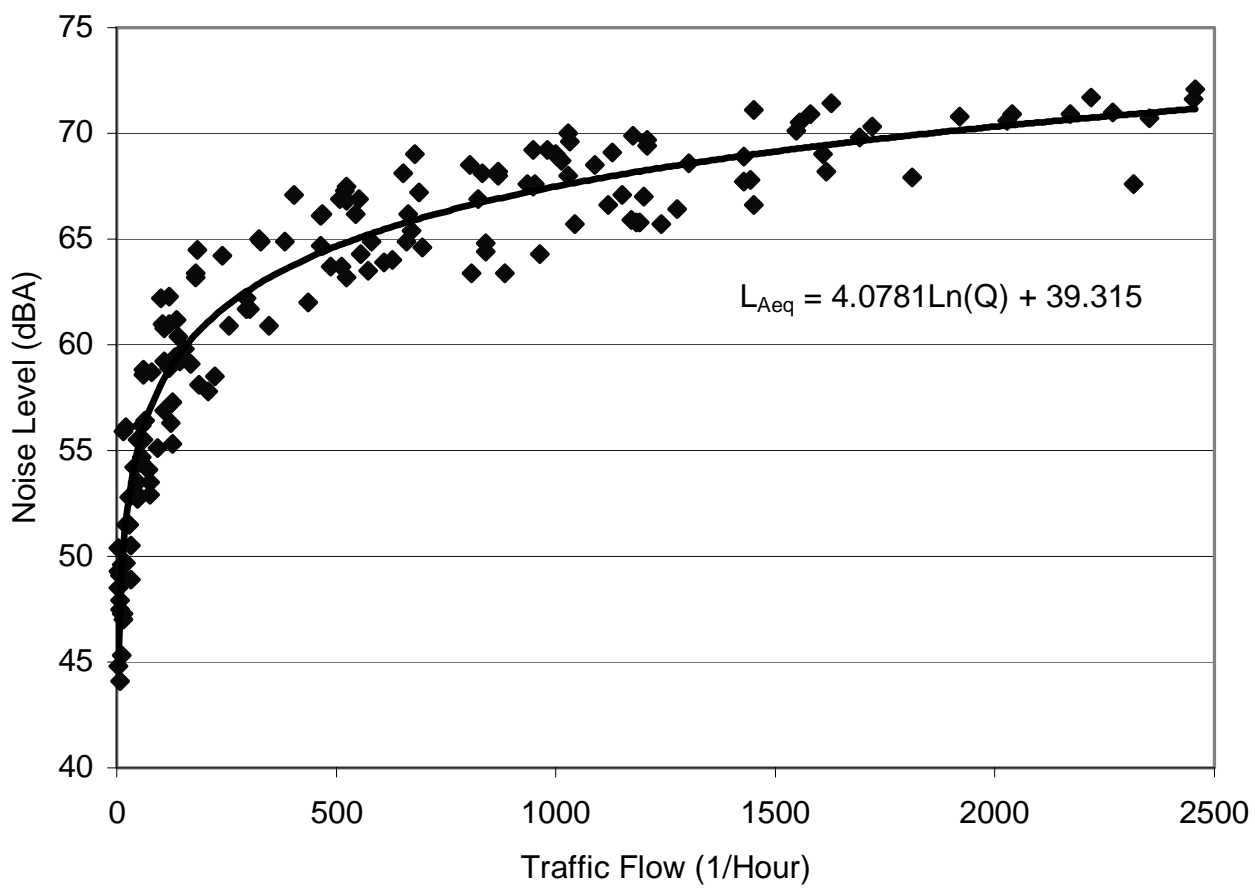

Figure 5. Logarithmic relationship between LAeq and Q. 
and doors could provide indoor sound level below the recommended limits. Per the standards of WHO, the noise level in the residential areas of Category III in the city can generally be considered acceptable. The areas in the central region of a residential area without public traffics provides good living environment from ambient noise point of view. Since large proportion of residential areas in Regina are adjacent to minor streets or lies away from major roads, the overall traffic noise level in Regina can be considered as acceptable with respect to the abovementioned standards.

A general form relationship between $\mathrm{L}_{\mathrm{Aeq}}$ and traffic flow $Q$ established in the research provides a good guidance for researchers and engineers to quantify the traffic noise intensity of a road with the traffic flow specified or control the traffic noise level by adjusting the traffic flow.

Acknowledgements. The authors wish to acknowledge the financial supports from the Canada Foundation for Innovation (CFI) and the University of Regina's Centre for Sustainable Communities. The authors are grateful to Mr. Glen Kovach of the Transportation Division, City of Regina, for the traffic flow data provided. Assistance from Ms. X. Yan and Mr. L. Xu in site measurements and data acquisition is highly appreciated.

\section{References}

Ali, S.A. and Tamura, A. (2003). Road traffic noise level, restrictions and annoyance in Greater Cairo, Egypt. Appl. Acoustics, 64, 815-823.

BCHEB (British Columbia, Highway Environment Branch), Wakefield Acoustics Ltd. and British Columbia, Ministry of Transportation and Highways (1996). Lions Gate crossing: South Shore Traffic Noise Study, The Branch, Victoria, BC.

Bruel \& Kjaer (1995 and 1998). Technical Documentation 2238 and 2260 Integrating and Logging Sound Level Meter, Denmark.

Bruel \& Kjaer (2000). Environmental Noise Booklet, Denmark.

Cao, J., Dai, L., Fan, L. and Mobed, N. (2004). Assessment of traffic noise impact on residential areas of Regina, Environmental Informatics Archives, Proc. of ISEIS 2004 International Conference, Regina, Canada, 2, pp. 456-463.

ETPB (Edmonton, Alberta, Transportation Planning Branch) (1974). Noise in the City of Edmonton, Transportation Planning Branch, Engineering \& Transportation Dept., City of Edmonton.

Epplett, C. and Gallagher, J. (1973). Motor Vehicle Traffic in Ottawa: Environmental Impact and the Energy/Transportation Interface, Pollution Probe, Ottawa.

Federal-Provincial Advisory Committee on Environmental and Occupational Health (1989). National Guidelines for Environmental Noise Control-Procedures and Concepts for the Drafting of Environmental Noise Regulations/By-laws in Canada, Minis- ter of Supply and Services Canada, Ottawa, Ontario.

Gaja, E., Gimenez, A., Sancho, S. and Reig, A. (2003). Sampling techniques for the estimation of the annual equivalent noise level under urban traffic conditions. Appl. Acoustics, 64, 43-53.

Harmelink, M.D. and Hajek, J.J. (1972). Noise Barrier Evaluation and Alternatives for Highway Noise Control, Ministry of Transportation and Communications, Downsview, Ontario.

Hajek, J.J. and Krawczyniuk, R. (1983). The Accuracy of Highway Traffic Noise Predictions, Research and Development Branch, Ontario Ministry of Transportation and Communications, Downsview, Ontario.

International Organization for Standardization (ISO) (1995). ISO Standards Handbook: Acoustics, International Organization for Standardization.

Johnston, G.W. and Carothers, R. (1974). Urban Traffic Noise Annoyance Measurements and Derived Indices, University of Toronto-York University Joint Program in Transportation, Toronto.

$\mathrm{Li}, \mathrm{B}$. and Tao, S. (2004). Influence of expanding ring roads on traffic noise in Beijing City. Appl. Acoustics, 65, 243-249.

Li, B., Tao, S. and Dawson, R.W. (2002). Evaluation and analysis of traffic noise from the main urban roads in Beijing. Appl. Acoustics, 63, 1137-1142.

Love, B.C. (1986). The Effect of Road Traffic Noise on Housing Prices in Calgary, 1978 to 1982, National Library of Canada, Ottawa.

Morillas, J.M.B., Escobar, V.G., Sierra, J.A.M., Gomez, R.V. and Carmona, J.T. (2002). An environmental noise study in the city of Caceres, Spain. Appl. Acoustics, 63, 1061-1070.

Onuu, M.U. (2000). Road traffic noise in Nigeria: Measurements, analysis and evaluation of nuisance. J. Sound Vibration, 233 (3), 391-405.

Pyplacz, B.M. (1983). Urban Traffic Noise Abatement: A Case Study of Boundary Road, Vancouver, BC, Student Report, University of British Columbia, School of Community \& Regional Planning, Vancouver.

Shaw, E.A.G. (1996). Noise environments outdoors and the effects of community noise exposure. Noise Control Eng. J., 44(3), 109-119.

Shaw, M.F. (1971). Truck Noise Pollution, Canadian Transport Commission Research Branch, Ottawa.

Sommerhoff, J., Recuero, M. and Suarez, E. (2004). Community noise survey of the city of Valdivia, Chile. Appl. Acoustics, 65, 643-656.

Traffic Division, City of Regina (2004). 2003 Traffic Flow Map. http://www.regina.ca/content/info_services/roads/traffic_flow.sh tml.

US Department of Housing and Urban Development (1985). The Noise Guidebook, Washington, DC, US Dept. of Housing and Urban Development.

World Health Organization (WHO) (1999). Guidelines for Community Noise, Geneva, Switzerland.

Zannin, P.H.T., Diniz, F.B. and Barbosa, W.A. (2002). Environmental noise pollution in the city of Curitiba, Brazil. Appl. Acoustics, $63,315-358$. 